\title{
Circumspectives Does Cannabis Cause, Exacerbate or Ameliorate Psychiatric Disorders? An Oversimplified Debate Discussed
}

\author{
Margaret Haney, ${ }^{*, 1}$ and A Eden Evins ${ }^{2}$ \\ 'Division on Substance Abuse, Department of Psychiatry, Columbia University Medical Center, New York, NY, USA; ' ${ }^{2}$ Center for Addiction Medicine, \\ Department of Psychiatry, Massachusetts General Hospital and Harvard Medical School, Boston, MA, USA
}

\begin{abstract}
There have been extensive policy shifts in the legality of recreational and therapeutic use of cannabis in the United States, as well as a steady increase in the number of people using the drug on a regular basis. Given these rapid societal changes, defining what is known scientifically about the consequences of cannabis use on mental health takes on added public health significance. The purpose of this circumspectives piece is to discuss evidence of cannabis' effects on two psychiatric conditions: post-traumatic stress disorder and psychotic disorders. Dr Haney and Dr Evins will discuss two viewpoints regarding the benefit and harm of cannabis use for these conditions, while outlining what remains unproven and requires further testing to move the field forward.

Neuropsychopharmacology (2016) 4I, 393-40I; doi:I0.1038/npp.2015.25I; published online I6 September 2015
\end{abstract}

Attitudes toward cannabis in the United States have undergone a substantive shift, with, for the first time in history, a majority of Americans favoring cannabis legalization. Nationwide, marked public opinion and policy changes are occurring in what is largely a scientific vacuum, with well-controlled, scientific evidence contributing little to the debate on legalization of cannabis for medical or recreational use. Even among scientists, debates on cannabis can be polarized and high in emotional content, making it difficult to distinguish evidence from hyperbole.

In adolescents, increased social acceptance and decreases in the perception of cannabis' risks are associated with increased use (Hall and Weier, 2015; Scheurmeyer et al, 2014). Already 2.6 million more people in the United States report near-daily cannabis use in 2013 compared with 2008 (Substance Abuse and Mental Health Services Administration (SAMHSA), 2014). And cannabis legalization creates a powerful profit motive to create and maintain cannabis users, with the burgeoning marijuana industry following a similar business strategy as the tobacco industry (Richter and Levy, 2014), which will likely further increase cannabis use.

In light of these major policy changes, defining what is known about the potential consequences of cannabis use has considerable public health significance and is the purpose of this circumspectives piece. We will discuss the influence of cannabis use on post-traumatic stress disorder (PTSD) and

*Correspondence: Dr M Haney, Professor of Neurobiology (in Psychiatry), New York State Psychiatric Institute, Columbia University Medical Center, I05I Riverside Dr, Unit 120, New York, NY I0032, USA, Tel: +212 543 6539, Fax: +212543 5991,

E-mailmh235@columbia.edu

Received 24 July 2015; revised 14 August 2015; accepted 17 August 2015; accepted article preview online 19 August 2015 psychotic disorders. Each author will present data supporting one perspective regarding the link between cannabis use and the course of these disorders, and they will then present their shared perspectives on critical studies needed to move the field forward. An important caveat: clearly, cannabis is a pharmacologically complex plant with constituents that have the potential for producing both positive and negative effects. We will take opposing positions to accommodate the circumspectives framework, but emphasize that there is considerable overlap and nuance in our viewpoints.

\section{PTSD}

\section{Meg Haney}

PTSD, an anxiety disorder that can develop following exposure to a traumatic event is characterized by persistent alarm and distress, numbing, avoidance, increased arousal, as well as aberrant memory processes. Hyperconsolidation of emotional memories or impaired extinction of fear memories can lead to intrusive recollections and the re-experiencing of the original traumatic event through flashbacks or nightmares (Sripada et al, 2013; Neumeister et al, 2013).

Many with PTSD report using cannabis to cope with anxiety, stress, and insomnia (Cougle et al, 2011; Boden et al, 2013). Consistent with a potential therapeutic effect, oral cannabinoids such as dronabinol (synthetic $\Delta^{9}$-tetrahydrocannabinol (THC), the primary psychoactive constituent of cannabis) and nabilone (a synthetic analog of THC), have been shown to reduce the acute response to fear stimuli as well as trauma-related symptomatology in those with PTSD. Nabilone reduced nightmares and improved sleep in both an open label and placebo-controlled trial, while also increasing 
clinician ratings of improvement and self-reported measures of well being (Fraser, 2009; Jetly et al, 2015). A retrospective study of nabilone for PTSD-related nightmares also showed promising results (Cameron et al, 2014).

But cannabinoids may do more than simply provide acute symptom relief. Unlike drugs such as alcohol, which may temporarily alleviate certain symptoms of PTSD while not affecting (or exacerbating) the underlying clinical condition, cannabinoid agonists specifically target the root cause of many PTSD symptoms: dysregulated threat responding and impaired extinction of fear-based memories (Passie et al, 2012; Marsicano et al, 2002; Ganon-Elazar and Akirav, 2009, 2012, 2013,). There is a dense expression of cannabinoid (CB1) receptors in amygdala-hippocampal-cortico-striatal circuits that have a role in anxiety, emotional learning and the consolidation of fear-related memories, as well as coordinating fear-related behavior (Lutz, 2007; Neumeister et al, 2013; Chhatwal et al, 2005). There is also a high density of CB1 receptors in the hippocampus, which mediates the retrieval of fear-related memories (Atsak et al, 2012), demonstrating a potential biological substrate for a therapeutic effect of cannabinoids in this population.

In patients with PTSD, the amygdala is hyperresponsive to threat-related or emotional stimuli, whereas the ventral/ medial prefrontal cortex and hippocampus are hypoactive, resulting in inadequate top-down control of amygdalar activation relative to healthy controls (Rauch et al, 2006; Etkin and Wager, 2007; Killgore et al, 2014). In fact, hypoactivity in the medial PFC was associated with greater symptom severity, and is suggested to reflect anxiety generalization and a deficit in emotional regulation (Etkin and Wager, 2007).

Cannabinoids modulate this threat response: in healthy volunteers, dronabinol attenuated amygdala reactivity to fear stimuli in a social-threat procedure without altering performance of complex tasks (Phan et al, 2008), suggesting cannabinoids selectively reduce threat responding. Similarly, cannabidiol (CBD), a non-intoxicating constituent of cannabis, attenuated the amygdala response to fearful faces (Fusar-Poli et al, 2009).

Endogenous cannabinoids also influence fear responding. Healthy individuals with higher basal levels of the endogenous cannabinoid anandamide, due to a common variant in the fatty-acid amide hydrolase (FAAH) gene, have enhanced fronto-amygdala connectivity and fear extinction learning, as well as reduced anxiety-like behaviors (Dincheva et al, 2015) and threat-related amygdala reactivity (Hariri et al, 2009). Patients with PTSD have altered levels of both CB1 receptors and plasma levels of endogenous cannabinoids (Hill et al, 2013; Neumeister et al, 2013), which may contribute to heightened alarm and other PTSD symptoms. It is telling that patients maintained on CB1 antagonists for the treatment of obesity were over three times more likely to discontinue treatment because of mood-related side effects (primarily anxiety) relative to placebo (Christensen et al, 2007; Moreira et al, 2009), illustrating the role of endocannabinoids in mood regulation.

In terms of fear extinction, the importance of the CB1 receptor has been best demonstrated in a series of preclinical studies, showing that CB1 knockout mice learned and could recall the association between a tone and an electric shock but were unable to extinguish this pairing despite elevated levels of endocannabinoids in the basolateral amygdala (Marsicano et al, 2002; Chhatwal et al, 2005). Cannabinoid agonists, conversely, facilitated extinction in preclinical models of PTSD (de Bitencourt et al, 2013): agonist administration within $24 \mathrm{~h}$ of exposure to stressful stimuli prevented the development of enhanced acoustic startle response, impaired extinction, and an altered neuroendocrine stress response, as compared with placebo administration (Korem and Akirav, 2014).

In human laboratory studies, dronabinol facilitated fear extinction. In a placebo-controlled, double-blind study, healthy non-cannabis using volunteers learned to associate two visual stimuli with an aversive white noise burst. The next day, participants were treated with placebo or dronabinol $2 \mathrm{~h}$ prior to an extinction session. Those treated with dronabinol had less reinstatement of fear responding $24 \mathrm{~h}$ later relative to the placebo group (Rabinek et al, 2013). Given that exposure therapy to treat PTSD is often associated with poor extinction retention (eg, Milad et al, 2009), these data suggest that cannabinoid administration during extinction training might reduce the reinstatement of fear responding. CBD may also enhance consolidation of extinction learning (Das et al, 2013), perhaps by inhibiting FAAH and thereby boosting endocannabinoid levels (Leweke et al, 2012; de Bitencourt et al, 2008).

In sum, a therapeutic goal for the treatment of PTSD is to reduce threat responding and to re-learn emotional memories to reduce their aversive intensity. Existing data suggest that endogenous and exogenous cannabinoid agonists both acutely improve stress reactivity and reduce responding to perceived threats and facilitate extinction of fear responding, supporting further research of cannabinoid agonists for clinical treatment of PTSD.

\section{Eden Evins: PTSD}

As of January 2015, 23 states have passed legislation allowing possession of smoked cannabis for medical purposes. There is evidence from human studies of a correlation between regular cannabis use and a range of potentially adverse outcomes, including adverse effects on learning and cognition (Solowij and Battisti, 2008; Solowij et al, 2011), effects on brain structure and function (Lorenzetti et al, 2014, 2015; but see Weiland et al, 2015), negative psychiatric impact (Hall and Degenhardt, 2009), and addiction (Anthony, 2006; Lopez-Quintero et al, 2011), particularly among daily users, where it is estimated that $25-50 \%$ will become dependent (Hall and Degenhardt, 2009; Hall, 2009). Nearly all of these studies, however, assess recreational, and not medical, cannabis use. Virtually nothing is known about potential effects of medical cannabis that is used instead of, or complementary to, traditional medicine for disorders such as pain, insomnia, anxiety, depression, and PTSD. Data are also lacking on whether those who use cannabis daily for chronic conditions also develop similar rates of addiction to those who use cannabis daily for recreational purposes.

Although legislation in many states provides very broad conditions for which 'medical' cannabis may be made available, PTSD, specifically, is being or has been added to the list of conditions in Arizona, Connecticut, Delaware, Michigan, and Nevada. Although preclinical data on effects of cannabinoids on consolidation of fear-related memory 
and particularly on extinction are intriguing and should be pursued in well-controlled trials in people with PTSD, the current evidence base for safety and efficacy for use of cannabis for psychiatric disorders, in general, and PTSD, in particular, is exceedingly thin. The American Psychiatric Association has taken the position that 'There is no current scientific evidence that marijuana is in any way beneficial for the treatment of any psychiatric disorder. In contrast, current evidence supports, at minimum, a strong association of cannabis use with the onset of psychiatric disorders. Adolescents are particularly vulnerable to harm, given the effects of cannabis on neurological development.'

PTSD is a serious, often debilitating illness for which currently available treatments are effective but often leave people with residual symptoms, for which some may turn to cannabis. For example, cognitive behavioral therapy (CBT) and prolonged exposure (PE) therapy are proven effective behavioral treatments for PTSD, but symptom reduction with inpatient PTSD treatment, particularly for symptoms of numbing, is inversely correlated with cannabis use following inpatient treatment (Bonn-Miller and Vujanovic, 2011). This provides evidence that improved treatments for PTSD is needed, not that cannabis is effective. In fact, a longitudinal cohort study in 2276 veterans reported outcomes in four groups, classified on their cannabis use as (i) those not using before treatment or 4 months after discharge, 'never used', (ii) those using at admission but not after discharge 'stoppers', (iii) those using after discharge but not at admission, 'starters', and (iv) those using at both time points before and after treatment, 'continuing users'. Adjusting for relevant covariates, cannabis use was associated with greater PTSD symptom severity, more violent behavior, and more alcohol and drug use in the group as a whole. Stoppers and never users had the lowest PTSD symptoms, whereas starters had the highest levels of violent behavior (Wilkinson et al, 2014). Thus, initiating cannabis use after initiating treatment was associated with worse PTSD symptoms, more violent behavior, and alcohol use. The authors concluded that cannabis may actually worsen PTSD symptoms or nullify the benefits of specialized intensive treatment, and that cessation or prevention of use may be an important goal of treatment, but this was a naturalistic study and controlled trials are needed, particularly in relatively cannabis-naive patients.

A retrospective study of PTSD symptoms in the first 80 people to obtain medical cannabis for PTSD in New Mexico suggested that self-reported symptoms were lower when smoking cannabis (Greer et al, 2014). However, inclusion criteria for this study included self-report of 'significant relief of several major PTSD symptoms when using cannabis.' Participants were asked to report PTSD symptom severity retrospectively when not using cannabis, and this served as the control condition. It is not surprising and not particularly meaningful that retrospective ratings of PTSD symptoms pre-cannabis use were higher than during cannabis use in a sample that had to report relief of PTSD symptoms with cannabis to be included. Controlled trials with methodological rigor are sorely needed in this field, particularly considering the potential for cannabis-related adverse effects on cognition and addiction in these patients (Silins et al, 2013). Those with PTSD who use cannabis experience greater problems associated with cannabis use than those without PTSD (Boden et al, 2013). Given the significant potential adverse effects of use of cannabis for PTSD, including worsening of potentially life-threatening symptoms of the illness itself, prospective trials are urgently needed to assess safety and efficacy of cannabinoids for this use. The efficacy of cannabinoids, available as FDA-approved medications, dronabinol, and nabilone, should be studied for primary and residual symptoms of PTSD, alone and in combination with CBT or PE.

\section{Haney and Evins: Moving the Field Forward}

The two authors agree that given the central role of endocannabinoids in the neurocircuitry mediating the response to emotionally salient stimuli and emotional learning, there is a potential clinical utility of cannabinoid agonists in PTSD treatment: CB1 agonists may reduce anxiety, improve sleep, and enhance extinction of traumarelated memories.

In terms of advancing the field, placebo-controlled studies testing a range of oral cannabinoid doses during extinction training are needed, as are studies demonstrating the optimal time window for this intervention (Ganon-Elazar and Akirav, 2009,2012). In theory, cannabinoid agonists administered in temporal proximity to the stressor would prevent the over-consolidation of fear memory, but this needs further testing (Trezza and Campolongo, 2013). The finding that dronabinol attenuated amygdala reactivity to fear stimuli in healthy controls should be repeated in those with PTSD. In addition to analogs of THC, studies testing CBD for discrete PTSD symptoms are needed, as is further research of FAAH inhibition (Kathuria et al, 2003), given the 'on demand' nature of endocannabinoid release (Gunduz-Cinar et al, 2013). Both CBD and FAAH inhibitors might maximize the therapeutic potential of cannabinoids for PTSD without risking the abuse-related or cognitive side effects of THC.

Overall, there are several advantages to slow-onset, long-duration, FDA-approved oral cannabinoids, rarely discussed in the debates about medical cannabis. First, oral cannabinoids have low abuse liability relative to smoked cannabis. A considerable subset of daily cannabis smokers develop a cannabis-use disorder (CUD), characterized by withdrawal symptoms, functional impairment, and difficulty maintaining abstinence, and using cannabis to cope with anxiety, in particular, is associated with an increased risk for developing CUD (Johnson et al, 2010). Inhaled cannabis also produces more deleterious effects on cognitive performance than oral administration (Ranganathan and D'Souza, 2006), which would be counter-therapeutic for PTSD. Also, cannabis withdrawal symptoms (disrupted sleep, anxiety, irritability; Haney et al, 1999, 2005; Budney et al, 2004) may be especially troublesome for PTSD patients, perhaps explaining why those with PTSD are more likely to relapse to cannabis use relative to controls (Bonn-Miller and Vujanovic, 2011). A second benefit of oral cannabinoids is that although cannabis marketers target particularly strains of cannabis toward patients for a range of medical conditions, the products sold rarely contain the cannabinoid concentrations advertised (Vandrey et al, 2015). Thus, in the absence of well-controlled data and product regulation, advertising is all that consumers and physicians currently have to make medical decisions regarding the clinical use of cannabis. 
Controlled trials testing the effects of smoked cannabis on PTSD outcomes have not been conducted, to our knowledge. A concern with state-by-state allowances for medical cannabis use for the treatment of PTSD is that patients would begin using the drug in the absence of controlled evidence of efficacy or recommended timing of administration, particularly in terms of facilitating extinction. Given the potential for adverse effects of smoked cannabis, we call for a slowing in the pace of legalization of cannabis for therapeutic use until safety and efficacy data exist to enable evaluation of risks and benefits of cannabinoids for specific features of PTSD.

A final point is that both oral and smoked cannabinoids can be anxiogenic, particularly for those who do not use cannabis regularly (eg, Haney, 2007). Although regular cannabis smokers often report smoking for relaxation and tension relief, anxiety, and panic following cannabis use are not uncommon and in fact drive the high rates of emergency room visits attributed to cannabis use (Moreira et al, 2009; Crippa et al, 2009; Hall and Solowij, 1998). This raises the possibility that oral or smoked cannabinoids would worsen anxiety in some PTSD patients. Clearly, FDA-approved treatments for PTSD (antidepressants, anticonvulsants, atypical antipsychotics, benzodiazepines) have the potential to worsen mood as well. If cannabinoid agonists are proven beneficial, the risk/benefit of each approach would have to be weighed with the understanding that increased anxiety is a possible outcome from cannabinoid use.

\section{PSYCHOTIC DISORDERS}

\section{Eden Evins}

It is clear that THC can cause acute psychotic symptoms, such as paranoia, in a dose-dependent manner (D'Souza et al, 2004; Murray et al, 2013), and those with a psychotic illness who do not stop using cannabis have a poorer prognosis on average than those who do (Tarricone et al, 2014; Alvarez-Jimenez et al, 2012), controlling for other substance use (Foti et al, 2010). What is somewhat controversial is whether to draw causal inference from the now well-replicated finding from large, prospective, longitudinal, epidemiologic studies that cannabis use, particularly heavy adolescent use of high potency cannabis, is associated with increased odds of developing schizophrenia (Andreasson et al, 1987; Arseneault et al, 2002; Di Forti et al, 2009, 2013; Fergusson et al, 2003; Giordano et al, 2014; Large et al, 2011; van Os et al, 2002; Zammit et al, 2002; Stefanis et al, 2014). There is a well-replicated dose effect, such that daily use and use of high THC potency cannabis further increase odds of developing a psychotic illness and of earlier onset of psychosis (Di Forti et al, 2009, 2013, 2015). Galvez-Buccollini and colleagues (2012) found a direct association between age of onset of cannabis use and age of onset of psychosis.

While presence of schizophrenia prodrome confounds establishment of precise onset of schizophrenia illness, and those in the prodrome may be more likely to use intoxicants (Giordano et al, 2014; DeLisi et al, 1991), strong evidence that cannabis exposure preceded onset of psychosis by up to 7 years has been reported in several large studies, controlling for or removing those with other drug use (Andreasson et al, 1987; Di Forti et al, 2009; Fergusson et al, 2003). Control for familial risk of schizophrenia attenuates but does not eliminate the association between cannabis use and schizophrenia, further supporting the hypothesis that cannabis exposure, particularly early, frequent exposure to high THC potency cannabis is a causal factor in the development of schizophrenia (Giordano et al, 2014).

Interactive effects between genotype, cannabis use, and psychosis suggest that cannabis use confers far greater risk of psychosis for some, in some cases a five- to sevenfold greater risk among daily users. Among cannabis users and daily cannabis users, respectively, carriers of the DRD2, rs1076560, $\mathrm{T}$ allele had three- and fivefold increased odds of developing a psychotic disorder compared with cannabis users who were GG carriers (Colizzi et al, 2015). Carriers of the COMT valine158 (Val) allele were more likely to develop schizophreniform disorder if they used cannabis in adolescence, although cannabis use had no influence on individuals homozygous for the methionine (Met) allele (Caspi et al, 2005). In a randomized clinical trial, COMT Val allele carriers experienced greater cognitive impairment with THC $(300 \mu \mathrm{g} / \mathrm{kg})$, and more psychotic symptoms in those prone to psychosis compared with placebo than Met allele carriers (Henquet et al, 2006). An AKT1 genotype by cannabis use interaction has also been reported, with those with C/C rs2494732 genotypes who used cannabis having twofold odds of having a psychotic disorder (van Winkel and Genetic $\mathrm{R}$, Outcome of Psychosis I, 2011). In another study, those with AKT1 C/C genotype with prior cannabis use and daily use, respectively, showed two- and sevenfold increased likelihood of a psychotic disorder compared with users and daily users who were T/T carriers (Di Forti et al, 2012).

There is evidence that individuals with or vulnerable to psychosis have a neurobiological response to THC that renders them more vulnerable to psychotogenic effects of cannabis. Those with psychotic disorder and their siblings are more sensitive than matched controls to the psychotogenic effects of acute THC administration (D'Souza et al, 2005; Schizophrenia Working Group of the Psychiatric Genomics Consortium, 2014). This may explain why even among those taking medications for psychotic disorders, cannabis use is associated with an increased risk of relapse into psychotic symptoms (Alvarez-Jimenez et al, 2012). Inhalation of vaporized THC ( $8 \mathrm{mg}$ ) by cannabis users with a psychotic disorder (not on medication) and those with firstdegree relatives with a psychotic disorder showed significantly greater striatal DA release following THC administration than control cannabis users without psychiatric illness, despite having a similar subjective response to THC (Kuepper et al, 2013). Therefore, although a common argument against causality is that cannabis use has risen considerably in the past 40 years, whereas rates of schizophrenia have not (eg, Frisher et al, 2009; Degenhardt et al, 2003; but see Hickman et al, 2007), its impact in the general population would be expected to be modest if cannabis precipitates psychosis preferentially in those with specific genetic vulnerability (Hall, 2014).

Thus, although schizophrenia etiology is multifactorial, and the majority of people who use cannabis do not develop schizophrenia, these findings, taken together, support the hypothesis that cannabis use, particularly frequent use of high THC content cannabis, increases the risk for development of psychosis, particularly in those with genetic 
susceptibility that influences vulnerability to environmental exposures. This warrants serious consideration from the point of view of public health policy (Radhakrishnan et al, 2014).

\section{Meg Haney}

Although heavy cannabis use by individuals with a psychotic disorder or vulnerable to one is largely associated with a poorer prognosis, there are sufficient reasons to question the causality of this relationship. To start, it is important to emphasize that although meta-analyses show a consistent association between cannabis use and psychotic disorders, the odds ratio is small. For those ever using cannabis, the association with psychotic disorders is 1.41 (95\% CI $1.20-1.65$ ), whereas the odds ratio is 2.09 (95\% CI 1.54-2.84) for those using cannabis frequently (Moore et al, 2007). As noted by Moore et al (2007), larger effect sizes have been reported in other analyses, but these were based on crosssectional data or were not adjusted for factors such as cumulative cannabis use, presence of psychiatric illness at baseline, other concurrent drug use, or cannabis use at least once $v s$ dependence (Arseneault et al, 2002; Henquet et al, 2005, Semple et al, 2005). Thus, an association between cannabis and psychosis exists, but, at best, it is only one small factor in a much larger constellation of factors associated with this disorder.

So why might a diagnosis of schizophrenia be associated with higher rates of cannabis use relative to the general population (Foti et al, 2010)? As noted above, the apparent dose-response relationship between amount of cannabis smoked and the likelihood of a disorder is one piece of evidence consistent with causality. The more cannabis used at baseline in large prospective studies, the greater the risk of developing schizophrenia or psychotic symptoms (Zammit et al, 2002; van Os et al, 2002; Fergusson et al, 2003) and the greater likelihood that psychotic symptoms at baseline persist (Henquet et al, 2005).

Yet, psychotic disorders rarely emerge without warning. Even when cannabis use unequivocally predates a diagnosis, schizophrenia is a neurodevelopmental disorder with origins in early development. Those destined to develop schizophrenia exhibit unusual thoughts and behaviors years before they develop delusions and hallucinations (Schiffman et al, 2005). This presents the possibility that, prior to a diagnosis of psychotic disorder and perhaps even prior to the prodrome phase of schizophrenia, those who have unusual thoughts or behaviors smoke more cannabis than those without these features; if this is the case, then a doseresponse relationship, ie, heavier cannabis use prior to a diagnosis, does not support a causality association but could reflect heavier use by those neurodevelopmentally vulnerable to developing a psychotic disorder.

Why would individuals at clinical high risk of psychosis or those with schizophrenia smoke cannabis? One reason may be to attenuate negative symptoms (eg, social withdrawal, anhedonia) poorly managed by antipsychotics. This hypothesis of self-medication has been disputed because there is no correlation between early symptoms of the disorder and cannabis use (Malone et al, 2010) or between cannabis use and psychotic symptoms or negative mood (Henquet et al, 2010). Yet, if patients are self-medicating negative or subtle mood symptoms, this correlation could be missed by retrospective reports or prospective monitoring of positive psychotic symptoms.

Another argument levied against the self-medication hypothesis is that individuals seeking treatment for a psychotic episode are more likely to smoke cannabis high in THC and low in CBD, a cannabinoid with potential antipsychotic effects (Leweke et al, 2012) as compared with control volunteers (Di Forti et al, 2013). The authors suggest that since high THC can worsen psychotic symptoms, patients with schizophrenia would not choose a type of cannabis high in THC to self-medicate their symptoms.

Yet, whether cannabis worsens or ameliorates certain symptoms of schizophrenia, it remains a drug of abuse, producing positive subjective and reinforcing effects regardless of psychiatric diagnosis. In fact, there is evidence that cannabis produces greater positive subjective effects in patients with schizophrenia or those prone to a psychotic disorder than in healthy controls. A study tracking mood each day using momentary assessments reported that those with schizophrenia were more sensitive to both the moodenhancing (lower negative affect) and the psychosisenhancing (auditory hallucinations) effects of cannabis than healthy controls (Henquet et al, 2010). Similarly, we found that participants who were clinically at high risk for developing schizophrenia showed larger increases in both intoxication and anxiety and paranoia following controlled cannabis administration relative to matched healthy controls (Vadhan et al, 2013). Although symptoms of psychosis were worsened by cannabis, mood was elevated to a greater extent than in controls, and this elevated mood might contribute to the consistent association between psychotic disorders and cannabis use. Thus, evidence that individuals who develop schizophrenia are more likely to smoke cannabis with high THC concentrations than those who do not develop schizophrenia may simply demonstrate that this population favors more potent and reinforcing strains of cannabis, regardless of $\mathrm{CBD}$ content.

In terms of the interaction between genetic vulnerability and cannabis use, the link between COMT alleles and vulnerability to psychosis (Caspi et al, 2005; Henquet et al, 2006) has been deemed 'very weak' upon subsequent analysis (Moore et al, 2007). A comparison of relatives of individuals with schizophrenia who smoked cannabis versus those relatives who did not did smoke cannabis showed that both groups were more likely to develop the illness compared with relatives of healthy controls regardless of cannabis use (Proal et al, 2014), which does not support the hypothesis that cannabis worsens outcome in individuals genetically vulnerable to psychosis.

It may be that rather than a causal link, there are shared genetic and environmental risk factors for schizophrenia and cannabis use or for drug use in general. An association between schizophrenia risk alleles and cannabis use has been reported (Power et al, 2014), supporting a shared genetic etiology, and there are a number of demographic risk factors in common for cannabis use disorder and schizophrenia, such as being male with low socioeconomic status and educational attainment (DeRosse et al, 2010).

At last, in assessing the interaction between cannabis and psychotic disorder, it is useful to consider tobacco cigarette smoking in this population, as tobacco is more strongly 
linked to schizophrenia than cannabis. In a meta-analysis assessing tobacco use among patients with first-episode psychosis, there was a strong association $(\mathrm{OR}=6.04 ; 95 \% \mathrm{CI}$, 3.03-12.02) compared with healthy controls (Myles et al, 2012). Similar to the data with cannabis, patients with first-episode psychosis usually smoked tobacco cigarettes for some years prior to the onset of psychosis, have high prevalence of tobacco use when presenting for treatment, and are more likely to smoke than aged-matched controls (Myles et al, 2012). Also similar to cannabis, some suggest this association reflects the underlying neurobiology of psychotic disorders, which may enhance nicotine reinforcement; or those with schizophrenia use cigarettes to moderate the effects of the illness and the antipsychotic medications (eg, Dalack et al, 1998). Conversely, Kendler and colleagues (2015) recently presented evidence supporting the idea that tobacco use prospectively increases the risk of schizophrenia. These authors thoughtfully considered the same factors argued to support a cannabis-schizophrenia link, but acknowledge that the data support but do not prove causality. They also demonstrate that familial/genetic factors contribute to the association between tobacco use and schizophrenia.

To conclude, public perception and popular media often interpret associations shown in longitudinal studies as demonstrating causation, so the scientific community has to consistently emphasize the distinction between association and causation. Given the low odds ratio and evidence that schizophrenia is a neurodevelopmental disorder, the most scientifically conservative stance is that the association between cannabis and psychotic disorders is not causal. As described by Dumas et al (2002), there are three possible models explaining the cannabis-schizotypal link: (1) cannabis use increases risk for schizotypal traits; (2) schizotypal traits increase risk for cannabis use; (3) a third causal variable underlies both cannabis use and schizotypal traits. The data do not demonstrate causality but may reflect self-medication or a shared risk factor.

\section{Haney and Evins: Moving the Field Forward}

Despite differing on their interpretation of the evidencesupporting causality, the authors agree on the biological plausibility of a causal relationship between adolescent cannabis use and negative psychiatric outcome. CB1 cannabinoid receptors are the most common G-coupled protein receptors in the brain, at concentrations 10-fold higher than opioid receptors, for example, and endocannabinoids are an abundant CNS neuromodulatory system (Passie et al, 2012). Further, adolescence is a critical time of synaptic and circuit development, and CB1 receptors are ubiquitous in the prefrontal cortex, a brain site heavily impacted by schizophrenia (Malone et al, 2010; Hill, 2014). Exogenous cannabinoid use could disrupt endocannabinoiddirected brain organization during this period of rapid development, impacting neurobiological and therefore psychiatric outcome. The authors therefore agree with those (eg, Moore et al, 2007) who argue that even without data to demonstrate causation, the potential for long-term brain changes by regular cannabis exposure during adolescence is sufficient to warn the public against the risk of adverse psychiatric outcomes with adolescent cannabis use.
The authors also share concern about the impact of extraordinarily high THC concentrations in new routes of THC administration, such as marijuana e-cigarettes and dabbing ( $>60 \% \mathrm{THC}$ ), which may heighten the likelihood of adverse psychiatric consequences, particularly if regular use begins in adolescence. Cannabis smokers typically adjust their inhalation patterns and smoking topography as a function of cannabis strength (eg, inhaling more forcefully on low potency than high potency cannabis cigarettes; Heishman et al, 1989; Cooper and Haney, 2009), but this titration would be difficult with new routes of very potent THC administration.

In terms of moving the field forward: further study of the gene-environment interaction could improve our understanding of the association between cannabis use and schizophrenia. Polygenic effects (Pan et al, 2015) from large genome-wide association studies (Schizophrenia Working Group of the Psychiatric Genomics Consortium, 2014) could be calculated for those who do or do not use cannabis to potentially clarify some of the shared genetic risks that may underlie the association. Prospective, longitudinal studies, with assessments commencing in youth prior to initiation of drug use that include family history, prospective and ongoing psychiatric evaluation, genetics and neuroimaging such as the upcoming $\mathrm{ABCD}$ study would contribute understanding of how cannabis use influences the onset of schizophrenia (albeit not definitively demonstrating causality). Given that intellectual and neuromotor abnormalities in childhood are evident long before a diagnosis of schizophrenia (Larson et al, 2010), it would be useful to capture these symptoms early in development to observe whether those who later smoke cannabis have a worse prognosis than a group with comparable childhood symptoms who do not smoke cannabis.

\section{FUNDING AND DISCLOSURE}

Dr Haney's research is funded by NIDA. She has received research support from Insys Therapeutics, Aelis Farma and Lifeloc Technologies. Dr Evins' research is funded by NIDA, NIMH, and NHLBI. She has received research support from Pfizer, Forum Pharmaceuticals, and GSK.

\section{ACKNOWLEDGMENTS}

Jennifer Tidey, $\mathrm{PhD}$ for thoughtful discussions of tobacco cigarette use and schizophrenia, and Gillinder Bedi, PsyD, Ziva Cooper, $\mathrm{PhD}$ and Matthew Hill, $\mathrm{PhD}$ for their insight on the topic of PTSD and cannabis.

\section{REFERENCES}

Akirav I (2013). Targeting the endocannabinoid system to treat haunting traumatic memories. Front Behav Neurosci 7: 1-3.

Alvarez-Jimenez M, Priede A, Hetrick SE, Bendall S, Killackey E, Parker AG et al (2012). Risk factors for relapse following treatment for first episode psychosis: a systematic review and meta-analysis of longitudinal studies. Schizophr Res 139: 116-128.

Andreasson S, Allebeck P, Engstrom A, Rydberg U (1987). Cannabis and schizophrenia: a longitudinal study of Swedish conscripts. Lancet 2: 1483-1486. 
Anthony JC (2006). Cannabis Dependence: its Nature, Consequences and Treatment. Cambridge University Press: Cambridge, UK.

Arseneault L, Cannon M, Poulton R, Murray R, Caspi A, Moffitt TE (2002). Cannabis use in adolescence and risk for adult psychosis: longitudinal prospective study. BMJ 325: 1212-1213.

Atsak P, Hauer D, Campolongo P, Schelling G, McGaugh J, Roozendaal B (2012). Glucocorticoids interact with the hippocampal endocannabinoid system in impairing retrieval of contexual fear memory. PNAS 109: 3504-3509.

Bitencourt RM, Pamplona FA, Takahashi RN (2008). Facilitation of contextual fear memory extinction and anti-anxiogenic effects of AM404 and cannabidiol in conditioned rats. Eur Neuropsychopharmacol 18: 849-859.

Boden MT, Babson KA, Vujanovic AA, Short NA, Bonn-Miller MO (2013). Posttraumatic stress disorder and cannabis use characteristics among military veterans with cannabis dependence. Am J Addict 22: 277-284.

Bonn-Miller MO, Vujanovic AA (2011). Cannabis use among military veterans after residential treatment for posttraumatic stress disorder. Psychol Addict Behaviors 25: 485-491.

Budney AJ, Hughes JR, Moore BA, Vandrey R (2004). Review of the validity and significance of cannabis withdrawal syndrome. Am J Psychiatry 161: 1967-1977.

Cameron C, Watson D, Robinson J (2014). Use of a synthetic cannabinoid in a correctional population for posttraumatic stress disorder-related insomnia and nightmares, chronic pain, harm reduction, and other indications. J Clin Psychopharmacol 34: 559-564.

Caspi A, Moffitt TE, Cannon M, McClay J, Murray R, Harrington H et al (2005). Moderation of the effect of adolescent-onset cannabis use on adult psychosis by a functional polymorphism in the catechol-O-methyltransferase gene: longitudinal evidence of a gene X environment interaction. Biol Psychiatry 57: 1117-1127.

Chhatwal JP, Davis M, Maguschak KA, Ressler KJ (2005). Enhancing cannabinoid neurotransmission augments the extinction of conditioned fear. Neuropsychopharmacology 30: 516-524.

Christensen R, Kristensen PK, Bartels EM, Bliddal H, Astrup A (2007). Efficacy and safety of the weight-loss drug rimonabant: a meta-analysis of randomised trials. Lancet 370: 1706-1713.

Colizzi M, Iyegbe C, Powell J, Ursini G, Porcelli A, Bonvino A et al (2015). Interaction between functional genetic variation of DRD2 and cannabis use on risk of psychosis. Schizophr Bull.

Cooper ZD, Haney M (2009). Actions of delta-9-tetrahydrocannabinol in cannabis: relation to use, abuse, dependece. Int Rev Psychiatry 21: 104-112.

Cougle JR, Bonn-Miller MO, Vujanovic AA, Zvolensky MJ, Hawkins KA (2011). Posttraumatic stress disorder and cannabis use in a nationally representative sample. Psychol Addict Behav 25: $554-558$

Crippa JA, Zuardi AW, Martín-Santos R, Bhattacharyya S, Atakan Z, McGuire $P$ et al (2009). Cannabis and anxiety: a critical review of the evidence. Hum Psychopharmacol 24: 515-523.

D'Souza DC, Abi-Saab WM, Madonick S, Forselius-Bielen K, Doersch A, Braley G et al (2005). Delta-9-tetrahydrocannabinol effects in schizophrenia: Implications for cognition, psychosis, and addition. Biol Psychiatry 57: 594-608.

D'Souza DC, Perry E, MacDougall L, Ammerman Y, Cooper T, $\mathrm{Wu}$ YT et al (2004). The psychotomimetic effects of intravenous delta-9-tetrahydrocannabinol in healthy individuals: Implications for psychosis. Neuropsychopharmacology 29: 1558-1572.

Dalack GW, Healy DJ, Meador-Woodruff JH (1998). Nicotine dependence in schizophrenia: clinical phenomena and laboratory findings. Am J Psychiatry 155: 1490-1501.

Das RK, Kamboj SK, Ramadas M, Yogan K, Gupta V, Redman E et al (2013). Cannabidiol enhances consolidation of explicit fear extinction in humans. Psychopharmacology (Berl) 226: 781-792. de Bitencourt RM, Pamplona FA, Takahashi RN (2013). A current overview of cannabinoids and gluccocorticoids in facilitating extinction of aversive memories: Potential extinction enhancers. Neuropharmacology 64: 389-395.

Degenhardt L, Hall W, Lynskey M (2003). Exploring the association between cannabis use and depression. Addiction 98: 1493-1504.

Degenhardt L, Hall W, Lynskey M (2003). Testing hypotheses about the relationship between cannabis use and psychosis. Drug Alcohol Depend 71: 37-48.

DeLisi LE, Boccio AM, Riordan H, Hoff AL, Dorfman A, McClelland J et al (1991). Familial thyroid disease and delayed language development in first admission patients with schizophrenia. Psychiatry Res 38: 39-50.

DeRosse P, Kaplan A, Burdick KE, Lencz T, Malhotra AK (2010). Cannabis use disorders in schizophrenia: Effects on cognition and symptoms. Schizophr Res 120: 95-100.

Di Forti M, Iyegbe C, Sallis H, Kolliakou A, Folcone MA, Paparelli A et al (2012). Confirmation that the AKT1 (rs2494732) genotype influences the risk of psychosis in cannabis users. Biol Psychiatry 72: 811-816.

Di Forti M, Marconi A, Carra E, Fraietta S, Trotta A, Bonomo M et al (2015). Proportion of patients in south London with firstepisode psychosis attributable to use of high potency cannabis: a case-control study. Lancet Psychiatry 2: 233-238.

Di Forti M, Morgan C, Dazzan P, Pariante C, Mondelli V, Marques TR et al (2009). High-potency cannabis and the risk of psychosis. Br J Psychiatry 195: 488-491.

Di Forti M, Sallis H, Allegri F, Trotta A, Ferraro L, Stilo SA et al (2013). Daily use, especially of high-potency cannabis, drives the earlier onset of psychosis in cannabis users. Schizophr Bull 40: 1509-1517.

Dincheva I, Drysdale AT, Hartley CA, Johnson DC, Jing D, King EC et al (2015). FAAH genetic variation enhances fronto-amygdala function in mouse and human. Nat Commun 6: 1-9.

Dumas P, Soaud M, Bouafia S, Gutknecth C, Ecochard R, Dalery J et al (2002). Cannabis use correlates with schizotypal personality traits in healthy students. Psychiatry Res 109: 27-35.

Etkin A, Wager TD (2007). Functional neuroimaging of anxiety: a meta-analysis of emotional processing in PTSD social anxiety disorder, and specific phobia. Am J Psychiatry 164: 1476-1488.

Fergusson DM, Horwood LJ, Swain-Campbell NR (2003). Cannabis dependence and psychotic symptoms in young people. Psychol Med 33: 15-21.

Foti DJ, Kotov R, Guey LT, Bromet EJ (2010). Cannabis use and the course of schizophrenia: 10-year follow-up after first hospitalization. Am J Psychiatry 167: 987-993.

Fraser GA (2009). The use of a synthetic cannabinoid in the management of treatment-resistant nightmares in posttraumatic stress disorder (PTSD). CNS Neurosci Ther 15: 84-88.

Frisher M, Crome I, Martino O, Croft P (2009). Assessing the impact of cannabis use on trends in diagnosed schizophrenia in the United Kingdom from 1996 to 2005. Schizophr Res 113: 123-128.

Fusar-Poli P, Crippa JA, Bhattacharyya S, Borgwardt SJ, Allen P, Martin-Santos R (2009). Distinct effects of $\Delta 9$-tetrahydrocannabinol and cannabidiol on neural activation during emotional processing. Arch Gen Psychiatry 66: 95-105.

Galvez-Buccollini JA, Proal AC, Tomaselli V, Trachtenberg M, Coconcea C, Chun J et al (2012). Association between age at onset of psychosis and age at onset of cannabis use in non-affective psychosis. Schizophr Res 139: 157-160.

Ganon-Elazar E, Akirav I (2009). Cannabinoid receptor activation in the basolateral amygdala blocks the effects of stress on the conditioning and extinction of inhibitory avoidance. J Neurosci 29: 11078-11088.

Ganon-Elazar E, Akirav I (2012). Cannabinoids prevent the development of behavioral and endocrine alterations in a rat model of intense stress. Neuropsychopharmacology 37: 456-466. 
Ganon-Elazar E, Akirav I (2013). Cannabinoids and traumatic stress modulation of contextual fear extinction and GR expression in the amygdala-hippocampal-prefrontal circuit. Psychoneuroendocrinology 38: 1675-1687.

Giordano GN, Ohlsson H, Sundquist K, Sundquist J, Kendler KS (2014). The association between cannabis abuse and subsequent schizophrenia: a Swedish national co-relative control study. Psychol Med 45: 407-414.

Greer GR, Grob CS, Halberstadt AL (2014). PTSD symptom reports of patients evaluated for the New Mexico Medical Cannabis Program. J Psychoactive Drugs 46: 73-77.

Gunduz-Cinar O, MacPherson KP, Cinar R, Gamble-George J, Sugden K, Williams B et al (2013). Convergent translational evidence of a role for anandamide in amygdala-mediated fear extinction, threat processing and stress-reactivity. Mol Psychiatry 18: $813-823$.

Hall W (2009). The adverse health effects of cannabis use: what are they, and what are their implications for policy? Int J Drug Policy 20: $458-466$.

Hall W (2014). What has research over the past two decades revealed about the adverse health effects of recreational cannabis use? Soc Study Addict 110: 19-35.

Hall W, Degenhardt L (2009). Adverse health effects of non-medical cannabis use. Lancet 374: 1383-1391.

Hall W, Solowij N (1998). Adverse effects of cannabis. Lancet 352: $1611-1616$

Hall W, Weier M (2015). Assessing the public health impacts of legalizing recreational cannabis use in the USA. Clin Pharmacol Ther 00: 1-9.

Haney M (2005). The marijuana withdrawal syndrome: diagnosis and treatment. Curr Psychiatry Rep 7: 360-366.

Haney M (2007). Opioid antagonism of cannabinoid effects: differences between marijuana smokers and nonmarijuana smokers. Neuropsychopharmacology 32: 1391-1403.

Haney M, Ward AS, Comer SD, Foltin RW, Fischman MW (1999). Abstinence symptoms following smoked marijuana in humans. Psychopharmacology 141: 395-404.

Hariri A, Gorka A, Hyde LW, Kimak M, Halder I, Ducci F et al (2009). Divergent effects of genetic variation in endocannabinoid signaling on human threat- and reward-related brain function. Biol Psychiatry 66: 9-16.

Heishman SJ, Stitzer ML, Yingling JE (1989). Effects of tetrahydrocannabinol content on marijuana smoking behavior, subjective reports, and performance. Pharmacol Biochem Behav 34: 173-179.

Henquet C, Krabbendam L, Spauwen J, Kaplan C, Lieb R, Wittchen HU et al (2005). Prospective cohort study of cannabis use, predisposition for psychosis, and psychotic symptoms in young people. BMJ 330: 11-15.

Henquet C, Rosa A, Krabbendam L, Papiol S, Fananás L, Drukker M et al (2006). An experimental study of catechol-o-methyltransferase Val158Met moderation of delta-9-tetrahydrocannabinol-induced effects on psychosis and cognition. Neuropsychopharmacology 31: 2748-2757.

Henquet C, van Os J, Kuepper R, Delespaul P, Smits M, à Campo J et al (2010). Psychosis reactivity to cannabis use in daily life: an experience sampling study. B J Psychiatry 196: 447-453.

Hickman M, Vickerman P, Macleod J, Kirkbride J, Jones PB (2007). Cannabis and schizophrenia: model projections of the impact of the rise in cannabis use on historical and future trends in schizophrenia in England and Wales. Addiction 102: 597-606.

Hill MN (2014). Clearing the smoke: What do we know about adolescent cannabis use and schizophrenia? J Psychiatry Neurosci 39: 75-77.

Hill MN, Bierer LM, Makotkine I, Golier JA, Galea S, McEwen BS (2013). Reductions in circulating endocannabinoid levels in individuals with post-traumatic stress disorder following exposure to the world trade center attacks. Psychoneuroendocrinology 38: 1-16.

Jetly R, Heber A, Fraser G, Boisvert D (2015). The efficacy of nabilone, a synthetic cannabinoid, in the treatment of PTSDassociated nightmares: a preliminary randomized, double-blind, placebo-controlled cross-over design study. Psychoneuroendocrinology 51: 585-588.

Johnson K, Mullin JL, Marshall EC, Bonn-Miller MO, Zvolensky M (2010). Exploring the mediational role of coping motives for marijuana use in terms of the relation between anxiety sensitivity and marijuana dependence. Am J Addict 19: 277-282.

Kathuria S, Gaetani S, Fegley D, Valiño F, Duranti A, Tontini A et al (2003). Modulation of anxiety through blockade of anandamide hydrolysis. Nat Med 9: 76-81.

Kendler KS, Lönn SL, Sundquist J, Sundquist K (2015). Smoking and schizophrenia in population cohorts of Swedish women and men: a prospective co-relative control studyAm J Psychiatry. AiA, $1-9$.

Killgore WDS, Britton JC, Schwab ZJ, Price LM, Weiner MR, Gold AL et al (2014). Cortico-limbic responses to masked affective faces across PTSD, panic disorder, and specific phobia. Depress Anxiety 31: 150-159.

Korem N, Akirav I (2014). Cannabinoids prevent the effects of a footshock followed by situational reminders on emotional processing. Neuropsychopharmacology 39: 2709-2722.

Kuepper R, Ceccarini J, Lataster J, van Os J, van Kroonenburgh M, van Gerven JMA et al (2013). Delta-9-tetrahydrocannabinolinduced dopamine release as a function of psychosis risk: ${ }^{18}$ F-fallypride positron tomography study. PLoS One 8: e70378.

Large M, Sharma S, Compton MT, Slade T, Nielssen O (2011). Cannabis use and earlier onset of psychosis: a systematic metaanalysis. Arch Gen Psychiatry 68: 555-561.

Larson MK, Walker EF, Compton MT (2010). Early signs, diagnosis and therapeutics of the prodromal phase of schizophrenia and related psychotic disorders. Expert Rev Neurother 10: 1347-1359.

Leweke FM, Piomelli D, Pahlisch F, Muhl D, Gerth CW, Hoyer C et al (2012). Cannabidiol enhances anandamide signaling and alleviates psychotic symptoms of schizophrenia. Transl Psychiatry 2: e94.

Lopez-Quintero C, Pérez de los Cobos J, Hasin DS, Okuda M, Wang S, Grant BF et al (2011). Probability and predictors of transition from first use to dependence on nicotine, alcohol, cannabis, and cocaine: results of the National Epidemiologic Survey on Alcohol and Related Conditions (NESARC). Drug Alcohol Depend 115: 120-130.

Lorenzetti V, Solowij N, Fornito A, Lubman DI, Yucel M (2014), The association between regular cannabis exposure and alterations of human brain morphology: an updated review of the literature. Curr Pharm Des 20: 2138-2167.

Lorenzetti V, Solowij N, Whittle S, Fornito A, Lubman DI, Pantelis C et al (2015). Gross morphological brain changes with chronic, heavy cannabis use. Br J Psychiatry 206: 77-78.

Lutz B (2007). The endocannabinoid system and extinction learning. Mol Neurobiol 36: 92-101.

Malone DT, Hill MN, Rubino T (2010). Adolescent cannabis use and psychosis: epidemiology and neurodevelopmental models. Br J Pharmacol 160: 511-522.

Marsicano G, Wotjak CT, Azad SC, Bisogno T, Rammes G, Cascio MG (2002). The endogenous cannabinoid system controls extinction of aversive memories. Nature 418: 530-534.

Milad MR, Pitman RK, Ellis CB, Gold AL, Shin LM, Lasko NB et al (2009). Neurobiological basis of failure to recall extinction memory in posttraumatic stress disorder. Biol Psychiatry 66: $1075-1082$

Moore THM, Zammit S, Lingford-Hughes A, Barnes TRE, Jones PB, Burke $\mathrm{M}$ et al (2007). Cannabis use and risk of psychotic or affective mental health outcomes: a systematic review. Lancet 370: 319-328. 
Moreira FA, Grieb M, Lutz B (2009). Central side-effects of therapies based on $\mathrm{CB}_{1}$ cannabinoid receptor agonists and antagonists: focus on anxiety and depression. Best Pract Res Clin Endocrinol Metab 23: 133-144.

Murray RM, Paparelli A, Morrison PD, Marconi A, Di Forti M (2013). What can we learn about schizophrenia from studying the human model, drug-induced psychosis? Am J Med Genet B Neuropsychiatr Genet 162B: 661-670.

Myles N, Newall HD, Curtis J, Nielssen O, Shiers D, Large M (2012). Tobacco use before, at, and after first-episode psychosis: a systematic meta-analysis. J Clin Psychiatry 73: 468-475.

Neumeister A, Normandin MD, Pietrzak RH, Piomelli D, Zheng MQ, Gujarro-Anton A et al (2013). Elevated brain cannabinoid $\mathrm{CB}_{1}$ receptor availability in post-traumatic stress disorder: a positron emission tomography study. Mol Psychiatry 18: $1034-1040$.

Pan W, Chen YM, Wei P (2015). Testing for polygenic effects in genome-wide association studies. Genet Epidemiol 39: 306-316.

Passie T, Emrich HM, Karst M, Brandt SD, Halpern JH (2012). Mitigation of post-traumatic stress symptoms by Cannabis resin: a review of the clinical and neurobiological evidence. Drug Test Analysis 4: 649-659.

Phan KL, Angstadt M, Golden J, Onyewuenyi I, Popovska A, de Wit H (2008). Cannabinoid modulation of amygdala reactivity to social signals of threat in humans. $J$ Neurosci 28: 2313-2319.

Power RA, Verweij KJ, Zuhair $M$ et al Genetic predisposition to schizophrenia associated with increased use of cannabis (2014). Mol Psychiatry 19: 1201-1204.

Proal AC, Fleming J, Galvez-Buccollini JA, DeLisi LE (2014). A controlled family study of cannabis users with and without psychosis. Schizophr Res 152: 283-288.

Rabinek CA, Angstadt M, Sripada CS, Abelson JL, Liberzon I, Milad MR et al (2013). Cannabinoid facilitation of fear extinction memory recall in humans. Neuropharmacology 64: 396-402.

Radhakrishnan R, Wilkinson ST, D'Souza DC (2014). Gone to potA review of the association between cannabis and psychosis. Front Psychiatry 5: 54.

Ranganathan M, D'Souza DC (2006). The acute effects of cannabinoids on memory in humans: a review. Psychopharmacology 188: 425-444.

Rauch SL, Shin LM, Phelps EA (2006). Neurocircuitry models of posttraumatic stress disorder and extinction: human neuroimaging research-past, present, and future. Biol Psychiatry 60: 376-382.

Richter KP, Levy S (2014). Big marijuana-lessons from big tobacco. $N$ Engl J Med 371: 399-401.

Schiffman J, Nakamura B, Earleywine M, LaBrie J (2005). Symptoms of schizotypy precede cannabis use. Psychiatry Res 134: $37-42$.

Schizophrenia Working Group of the Psychiatric Genomics Consortium (2014). Biological insights from 108 schizophreniaassociated genetic loci. Nature 511: 421-427.

Schuermeyer J, Salomonsen-Sautel S, Price RK, Balan S, Thurstone C, Min SJ et al (2014). Temporal trends in marijuana attitudes, availability and use in Colorado compared to nonmedical marijuana states: 2003-2011. Drug Alcohol Depend 140: $145-155$.
Semple DM, McIntosh AM, Lawrie SM (2005). Cannabis as a risk factor for psychosis: systematic review. J Psychopharmacol 19: 187-194.

Silins E, Hutchinson D, Swift W, Slade T, Toson B, Rodgers B (2013). Factors associated with variability and stability of cannabis use in young adulthood. Drug Alcohol Depend 133: $452-458$.

Solowij N, Battisti R (2008). The chronic effects of cannabis on memory in humans: a review. Curr Drug Abuse Rev 1: 81-98.

Solowij N, Jones KA, Rozman ME, Davis SM, Ciarrochi J, Heaven PC et al (2011). Verbal learning and memory in adolescent cannabis users, alcohol users and non-users. Psychopharmacology (Berl) 216: 131-144.

Sripada RK, Garfinkel SN, Liberzon I (2013). Avoidant symptoms in PTSD predict fear circuit activation during multimodal fear extinction. Front Hum Neurosci 7: 672.

Stefanis NC, Dragovic M, Power BD, Jablensky A, Castle D, Morgan VA (2014). The effect of drug use on the age at onset of psychotic disorders in an Australian cohort. Schizophr Res 156: 211-216.

Substance Abuse and Mental Health Services Administration (SAMHSA) (2014). Results from the 2013 National Survey on Drug Use and Health: Summary of National Findings NSDUH Series H-48, HHS Publication No. (SMA) 14-4863, Substance Abuse and Mental Health Services Administration: Rockville, MD, USA.

Tarricone I, Boydell J, Panigada S, Allegri F, Marcacci T, Minenna MG et al (2014). The impact of substance use at psychosis onset on First Episode Psychosis course: Results from a 1 year follow-up study in Bologna. Schizophr Res 153: 60-63.

Trezza V, Campolongo P (2013). The endocannabinoid system as a possible target to treat both the cognitive and emotional features of post-traumatic stress disorder (PTSD). Front Behav Neurosci 7: $1-5$.

Vadhan NP, Corcoran CM, Bedi GI, Lieberman JG, Haney M (2013). Marijuana smokers at clinical high-risk for schizophrenia exhibit an enhanced subjective, behavioral and physiological response to smoked marijuana. Comprehensive Psychiatry 54: e37.

Vandrey R, Raber JC, Raber ME, Douglass B, Miller C, Bonn-Miller MO (2015). Cannabinoid dose and label accuracy in edible medical cannabis products. J Am Med Assoc 313: 2491-2493.

van Os J, Bak M, Hanssen M, Bijl RV, de Graaf R, Verdoux H (2002). Cannabis use and psychosis: a longitudinal populationbased study. Am J Epidemiol 156: 319-327.

van Winkel R, Genetic R, Outcome of Psychosis I (2011). Family-based analysis of genetic variation underlying psychosisinducing effects of cannabis: Sibling analysis and proband followup. Arch Gen Psychiatry 68: 148-157.

Weiland BJ, Thayer RE, Depue BE, Sabbineni A, Bryan AD, Hutchison KE (2015). J Neurosci 35: 1505-1512.

Wilkinson ST, Radhakrishnan R, D'Souza DC (2014). Impact of cannabis use on the development of psychotic disorders. Curr Addict Rep 1: 115-128.

Zammit S, Allebeck P, Andreasson S, Lundberg I, Lewis G (2002). Self reported cannabis use as a risk factor for schizophrenia in Swedish conscripts of 1969: historical cohort study. BMJ 325: 1199. 